\title{
A propósito de la reciente sentencia del Tribunal Supremo de 25 de septiembre de 2020: la relación laboral en difícil equilibrio sobre dos ruedas
}

\author{
ALBERTO AYALA SÁNCHEZ \\ Profesor de Derecho del Trabajo y de la Seguridad Social \\ Universidad de Cádiz (España) \\ alberto.ayala@uca.es \\ https://orcid.org/0000-0003-4380-1441
}

Por fín llegó la resolución; la Sala IV del Tribunal Supremo a través de su Sentencia de 25 de septiembre de 2020, (recud. 4746/2019), ha declarado que la relación negocial que mantiene Glovo con sus repartidores tiene naturaleza laboral. La sentencia de la que vamos a dar noticia de manera breve, es la respuesta (y no será la única) al gran fenómeno tecnológico que desde hace unos años se está viviendo debido del auge de las Tecnologías de la Información y de la Comunicación (TICs), y que ha dado lugar a la denominada economía digital (gig economy), Economía que se encuentra en pleno desarrollo y que tiene unos importantes efectos socioeconómico y laborales, siendo uno de sus resultados la implementación de determinadas aplicaciones informáticas que originan, a su vez, el nacimiento de la llamada economía de plataformas.

La economía de plataforma ha supuesto -y supone- un reto importantísimo para los distintos operadores jurídicos, al objeto de poder encuadrar de manera cierta las relaciones jurídicas que tienen como protagonistas a las citadas plataformas digitales. A estos efectos y en términos genéricos, el «empleador digital» articula una serie de relaciones jurídicas con determinadas personas físicas. De entre todas las distintas categorías normativas que permite u ofrece el Derecho objetivo, los sujetos implicados se inclinaban, o imponía el más fuerte (Glovo), suscribir un contrato mercantil en donde el repartidor como sujeto material de la prestación de 
servicios se acoge (sin ninguna otra opción ofrecida por la plataforma) al marco jurídico dispuesto para el trabajador autónomo o autónomo económicamente dependiente.

Bajo estas premisas básicas la doctrina judicial se pronunció de manera dispar, aunque con cierta preponderancia a favor de reconocer que la relación jurídica que mantenía Glovo con sus repartidores era de naturaleza laboral. No obstante, esa discrepancia interpretativa en el seno de los Tribunales Superiores de Justicia abonaba el campo jurídico para presentar ante el Tribunal Supremo el pertinente recurso de casación en unificación de doctrina. Para plantear el citado recurso se impugnó la resolución del Tribunal Superior de Justicia de Madrid, de 19 de septiembre de 2019 (rec. 195/2019), que negaba al repartidor su condición de trabajador por cuenta ajena, sirviendo como resolución de contraste la sentencia dictada por el Tribunal Superior de Justicia de Asturias, de 25 de julio de 2019 (rec. 1143/2019), que sí reconocía al rider dentro del ámbito subjetivo del Estatuto de los Trabajadores (art. 1.1).

Ante esta tesitura, el Tribunal Supremo ha tenido que realizar una labor hermenéutica del art. 1.1 del Estatuto de los Trabajadores (ET). Tarea que se ha concretado en elegir una de las siguientes opciones. Una primera, realizar una interpretación restrictiva de las notas que caracterizan la relación laboral o, una decantarse por una segunda opción y llevar a término una operación exegética extensiva de los elementos que conforman la relación de trabajo. Esta última posibilidad es la que ha elegido el Tribunal Supremo al interpretar y aplicar, a nuestro particular modo de ver, de manera certera y apropiada el art. 1.1. del ET, norma capital de donde se infieren las notas características del contrato de trabajo, a saber: la dependencia y la ajenidad; siendo ambas notas las que permiten establecer la frontera entre el trabajo por cuenta ajena y el autónomo.

Pero, además, el Alto Tribunal para llegar a concluir que la relación jurídica entre los repartidores y Glovo tiene naturaleza laboral, enlaza de manera oportuna el apartado primero del artículo primero del ET con la presunción de laboralidad (art. 8.1 del ET), engarce que, por otro lado, ya lo había adelantado y expresado la doctrina al analizar el trabajo en las plataformas.

Tal vez para cierto sector de la doctrina se ha perdido, en primer lugar, la oportunidad de salirse de los moldes clásicos y haber enfocado la cuestión desde ópticas más innovadoras, revitalizando la figura del trabajador autónomo como trabajador económicamente dependiente de las economías de plataforma. Y segundo lugar, y sin perjuicio de la obligación que tienen los tribunales de resolver las controversias planteadas ante ellos (art. 1.7 Código civil), el Tribunal Supremo podría haber manifestado - obiter dicta- la hipotética insuficiencia normativa o, en su caso, podía haber realizado una sutil llamada al Gobierno para regular la situación objeto de esta litis a través de una relación laboral especial, como defiende determinado parte de la doctrina.

La Sentencia objeto de esta crónica para alcanzar la citada conclusión ofrece una extensa argumentación que, a nuestro modo de ver, se puede condensar en tres hitos fundamentales: el primero y crucial, definir qué hace la plataforma Glovo; en segundo lugar, identificar de manera real qué es lo que hacen cada uno de los sujetos de la relación, esto es, el verdadero contenido 
obligacional de las relaciones surgidas entre Glovo y los repartidores y, en último lugar, determinado e identificado cuál es ese contenido material en que se concreta la actividad de cada uno de los sujetos, aplicarles el marco normativo apropiado, que no es otro, que el art. 1.1 del ET.

A tenor de estas consideraciones y para determinar qué actividad desarrolla la plataforma, con carácter previo es oportuno indicar los sujetos que participan en el entramado negocial, pues la operatividad de la plataforma se basa en la presencia necesaria de tres elementos subjetivos. En primer término, está la plataforma cuyo objeto, en principio, es poner en contacto al cliente final con el repartidor; en segundo término, encontramos al repartidor/trabajador que es quien ofrece el servicio pretendido por el usuario final y, en tercer término, como último eslabón de la cadena se encuentra el cliente final o consumidor del servicio.

Ante semejante esquema subjetivo, la plataforma afirma que solo desarrolla labores de intermediación entre el cliente final y el repartidor, cuando lo cierto es que su actividad se concreta en ofrecer y prestar efectivamente determinados servicios de mensajería (FJ vigésimo primero).

Esta calificación queda justificada por la existencia de distintos elementos fácticos que quedan suficientemente probados. Entre otros, caben destacar: primero, que Glovo es titular de la plataforma siendo esta el principal y fundamental activo que permite desempeñar la actividad de reparto; segundo, el repartidor carece de una verdadera capacidad organizativa propia y autónoma, ya que de manera efectiva está sometido al ámbito rector de Glovo; tercero, la plataforma es quien determina cómo ha de hacerse tanto la recogida como la entrega de los productos y, de igual manera, ha determinado el precio y manera de pago del servicio.

De este modo se pone de relieve que el trabajador carece de la infraestructura pertinente para desarrollar la actividad productiva y bajo sus propios parámetros. El repartidor no desarrolla la prestación de servicios de manera autónoma, es decir, con sus propios criterios organizativos, sino todo lo contrario, su actividad se desenvuelve de conformidad con las directrices impartidas por Glovo a través del programa informático que gobierna la plataforma, siendo este el «elemento esencial» sobre el que giran, nacen y desarrollan las relaciones jurídicas entre las partes (FJ decimoséptimo).

En este sentido, la plataforma lejos de ser una mera intermediaria, es una verdadera empresa dotada de una estructura organizativa compleja, en donde se confunde la actividad desarrollada por los repartidores con el propio objeto empresarial, que no es otra que la actividad de reparto.

Fijado el papel real que desempeña la plataforma, el segundo hito que colma el Tribunal Supremo para llegar a calificar la relación jurídica entre Glovo y los repartidores de laboral, es esclarecer cuál es el contenido verdadero, que no formal, del negocio suscrito por las partes inmersas en el litigio casacional. En este sentido, el Tribunal Supremo comienza con toda una declaración de intenciones, señalando que, «los contratos son lo que son y no lo que las partes 
quieren que sean» (FJ noveno), es decir, el nomen iuris dado por los sujetos contratantes no les vincula ni a ellos mismo, y menos aún a los tribunales.

De esta manera, el Tribunal Supremo, sí se detiene a valorar qué tipo de obligaciones asumen los sujetos intervinientes a través de ese contrato mercantil. Para ello, examina y categoriza cada una de las obligaciones, derechos y prerrogativas que conforman el citado contrato, para de este modo, verificar si realmente su contenido es el propio de un arrendamiento de servicios.

Así, el Tribunal sopesa una serie de indicios para atribuir al repartidor su condición de trabajador por cuenta ajena. A estos efectos, divide aquellos indicios que determinan la dependencia (v.gr.: geolocalización con GPS, Glovo le indica al repartidor cómo ha de realizar la prestación, la facilitación de una tarjeta de crédito para que pudiera compra productos al usuario, la compensación de los tiempos de espera, las causas de resolución contractual son una traslación de los motivos de despido disciplinario, las facturas las elaboraba la plataforma) y aquellos que prueban la ajenidad de la prestación (v.gr.: la plataforma es la que tomaba todas las decisiones comerciales como el precio del servicio, la forma de pago, la remuneración que había que satisfacer a los repartidores, asume los riesgos y venturas del negocio).

Por el contrario, el Tribunal de Casación con base en los nombrados indicios no se deja persuadir por los presuntos elementos que podrían derivar en situar la relación extramuros al Derecho del Trabajo, como, por ejemplo, la posibilidad de rechazar tanto a clientes como a servicios. Esa realidad formal descrita y contenida en el contrato mercantil queda desvirtuada por la realidad material, al quedar acreditado que esa libertad es más bien aparente.

Esta libertad queda ensombrecida al acreditarse que estaba supeditada a un particular procedimiento de control del trabajo realizado por la plataforma (sancionador, desde nuestro punto de vista), en donde a través de un sistema de puntuación se valora positiva o negativamente con una frecuencia diaria los ingresos del trabajador, hecho tangible que influía y afectaba de manera directa a que el repartidor pudiera o no desarrollar su actividad en las horas con mayor demanda.

Conforme a lo expuesto, se establece un sistema productivo en donde es fundamental el número de servicios que realiza el trabajador/repartidor, servicios que a la postre le garantizarán cierto montante retributivo, pero a la par, le permitirá desarrollar su trabajo en las franjas horarias con mayor demanda (las denominadas «horas diamante»), todo ello bajo el estricto control, no físico, pero sí del programa informático que sustenta la plataforma.

Todo ello le lleva a concluir, que la plataforma es una mera empresa de prestación de servicios (de mensajería y de recadería), en donde lo realmente importante y crucial es la propiedad de la plataforma y su programa informático como factor esencial de producción que, además, es el que organiza en microtareas el resto de factores productivos. Estos solo tienen su razón ser bajo la dirección y organización de la plataforma, pues fuera de ella son absolutamente irrelevantes para participar en el mercado (bicicleta y teléfono móvil). En definitiva, la actividad desarrollada en el mercado por el repartidor no se puede entender sin que este entre y participe 
en el círculo rector que implementa la plataforma, por tanto, es una mera ficción que el trabajador goce de autonomía para gestionar su actividad laboral, por lo que el repartidor debe ser considerado como un trabajador por cuenta ajena.

Pues bien, todo esto se ha conseguido llevando a término una pertinente interpretación evolutiva y objetiva de las notas de dependencia y ajenidad (art. 1.1 del ET), en conjunción con la presunción de laboralidad (art. 8.1 del ET), exégesis que permite hacer progresar al ordenamiento jurídico y con la que se le da cumplida satisfacción al tercer hito planteado. La labor hermenéutica realizada por el Tribunal Supremo se resume magníficamente con las palabras de un eminente profesor: «sólo una interpretación objetiva es capaz de hacer frente a los problemas planteados por fenómenos y situaciones que el legislador histórico no ha conocido, ni ha tenido que conocer» (Díez-Picazo). 